\title{
Standardizing Management of Post-Dural Puncture Headache in Obstetric Patients: A Literature Review
}

\author{
Do T. Nguyen, Robin R. Walters \\ Department of Anesthesiology, University of Alabama at Birmingham, Birmingham, USA \\ Email: dotunguyen@uabmc.edu
}

Received 20 August 2014; revised 21 September 2014; accepted 18 October 2014

Copyright (C) 2014 by authors and Scientific Research Publishing Inc.

This work is licensed under the Creative Commons Attribution International License (CC BY). http://creativecommons.org/licenses/by/4.0/

(c) (i) Open Access

\begin{abstract}
Post-dural puncture headache continues to be a significant cause of morbidity in parturients. Despite being a common complication faced by many anesthesiologists, there is a lack of consensus regarding its management. Many still use traditionally taught treatments such as strict bed rest and aggressive hydration despite lack of evidence for their usage. Few are using newly tested treatments such as gabapentin and ACTH despite being proven effective in randomized controlled trials. Furthermore, when and how the epidural blood patch should be used is contentious between different practitioners. This review aims at answering what is the best strategy to manage post-dural puncture headache and proposes an evidence-based practice guideline.
\end{abstract}

\section{Keywords}

Post-Dural Puncture Headache, Epidural Blood Patch, Complication from Epidural Placement, Management of Dural Puncture

\section{Introduction}

Post-dural puncture headache classically presents as a postural headache that occurs after puncture of the dura. It has been over a century since we have known about post-dural puncture headache. It continues to be a significant cause of morbidity for patients and stress for physicians. However, there is still no consensus on a standard strategy for its management. Many physicians are left to their own device on deciding which treatment option is best. Furthermore, many of the treatment options taught during medical school and residency are outdated and ineffective. In the past two decades, there have been many new studies on the prevention and treatment of postdural puncture headache such as the use of intrathecal catheter, epidural morphine, intravenous gabapentin and 
ACTH, etc. As physicians, changing our practice to adapt to new evidence is pivotal, but we have a natural resistance to change. The purpose of this review is to look at the available evidence for the prevention and treatment of post-dural puncture headache and to formulate a practice guideline for this problem. The hope is that by having a guideline available for physicians to compare their practice to, it can help facilitate better evidencebased practices.

\section{Pathophysiology}

Knowledge of CSF leakage causing headache has been postulated since 1898 when Karl Bier correctly surmised this relationship based on his first-hand experience. The normal adult's total CSF volume is approximately 150 $\mathrm{ml}$, half of which is within the cranial cavity and half in the spinal canal. CSF production occurs mainly in the choroid plexus and about $500 \mathrm{ml}$ of CSF is produced daily as it gets reabsorbed. CSF pressure in the lumbar region varies greatly with position. In the horizontal position, the pressure is between 5 to $15 \mathrm{~cm}_{2} \mathrm{O}$. When assuming the erect position, this pressure increases to over $40 \mathrm{~cm} \mathrm{H}_{2} \mathrm{O}$ [1].

The spinal dura mater is a tough membrane and the outer most layer of the meninges that surround the brain and the spinal cord. When the dura mater is perforated, CSF will leak through it until it is closed either by intervention or through healing [1]. Healing of the dura mater is thought to be facilitated by fibroblastic proliferation of surrounding tissue and blood clots [2].

The mechanism by which CSF loss leads to a headache remains unclear, but there are two possible explanations. First, loss of CSF pressure can cause traction on intracranial structures upon assuming the erect position, leading to the symptoms. Second, decrease in CSF volume in the cranium leads to a compensatory venodilation via the Monro-Kellie doctrine. The doctrine states that the sum of CSF volume, brain volume, and intracranial blood volume remains constant, thus a fall in CSF volume would lead to an increase in intracranial blood volume by way of venodilation, causing the headache [1] [3].

The incidence of post-dural puncture headache varies depending on the type and size of the needle used. A cutting needle would increase the rate compared to a pencil-point needle since it causes more damage to the fibers of the dura. As fibers of the dura are cut, they retract under tension, leaving behind a larger defect. Examples of cutting needles are Quinke and Tuohy needles. Examples of pencil-point needles are Sprotte, Whitacre, and Gertie Marx. Dural puncture with a 22G Quinke has a PDPH incidence of 36\%, compared to a 22G Whitacre, in which the incidence is $0.6 \%$ - $4 \%$ [1] [4]-[7]. Since adopting the pencil point needle in obstetric anesthesia, the most common cause of severe headache now is accidental dural puncture with a Tuohy needle during epidural placement. In a large meta-analysis, Choi et al. showed that parturients have approximately a $1.5 \%$ risk of accidental dural puncture and of those, approximately 50\% developed PDPH [8]. Other studies since then have showed that after dural puncture with the Tuohy needle, the incidence of PDPH can be greater than 70\% [9] [10]. The higher incidence from the more recent studies is likely from an increase in our ability to diagnose PDPH.

\section{Diagnosis of Post-Dural Puncture Headache}

The post-dural puncture headache can usually be diagnosed with a history of dural puncture and a presentation of severe postural headache. The onset is usually within the first three days of the dural puncture $(90 \%$ of patients) and 66\% starts in the first 48 hours [1] [11] [12]. Characteristically, the headache is severe, usually distributed over the frontal and occipital areas, radiating to the neck and shoulders. The pain is exacerbated by head movements and assuming an upright position. It is relieved by lying down. Other symptoms that may be associated with the headache include nausea/vomiting, hearing loss, tinnitus, vertigo, dizziness, cranial nerve palsies, visual disturbances, arm pain and thoracic back pain [13]-[17]. Although unlikely, intracranial subdural hematomas from tears in the bridging veins, cerebral herniation, and death have been described as a result from dural puncture [18]-[20].

Usually, post-dural puncture headache is diagnosed based on the international headache society classification criteria (ICHD-II criteria). To meet criteria, the patient needs to have a headache within 15 minutes after sitting or standing and improves within 15 minutes of lying down. The patient would need at least one of the following symptoms in association with the headache: neck stiffness, tinnitus, hypacusia, photophobia, or nausea. The headache has to have developed within 5 days after a dural puncture. Finally, the headache should resolve spon- 
taneously within 1 week or within 48 hours of receiving effective treatment of the spinal fluid leak (usually by epidural blood patch) [21]. However, these criteria alone are not sensitive enough to pick up many patients with post dural puncture headaches. A recent study widened these criteria to include patients with postural neck ache with or without headache along with symptoms such as dizziness, tinnitus, and muffled hearing and they also extended the period of symptoms from 5 to 14 days. With these widened criteria, the sensitivity for detecting post-dural puncture headache increased from $36 \%$ to $71 \%$ and the positive predicted value increased from $69 \%$ to $88 \%$ when compared to ICDH-II criteria [22].

Other causes for headache should be considered especially when the patient does not present with postural features. Up to 39\% of parturients report symptoms of a headache unrelated to dural puncture following delivery [23]. Differential diagnosis includes pre-eclampsia, drugs withdrawal (i.e. caffeine), migraine, sinus headache, meningitis (viral, chemical, or bacterial), intracranial hemorrhage, cerebral infarction, intracranial tumor, pituitary apoplexy, cerebral sinus thrombosis, and non-specific headaches [1]. Some of these diagnosis may be life threatening, thus should be considered when the patient does not respond to treatment as expected.

\section{Management of Post-Dural Puncture Headache}

\subsection{State of Current Practice}

There continues to be a lack of consensus among anesthesiologists regarding the management of post-dural puncture headache [24]. In 2011, Baysinger et al. did a survey of anesthesiologists in North America regarding the management of post-dural puncture headache. The result showed that protocols are rare and management highly variable. Many anesthesiologists continue to use traditionally taught treatments including aggressive hydration, oral caffeine, NSAIDS, and bed rest despite lack of evidence supporting these therapies. In addition, most anesthesiologists also avoid new techniques that have showed promising result such as IV cosyntropin and neuraxial morphine [25]. Moreover, 80\% of respondents reported abandoning conservative therapy and administering epidural blood within 24 hours of dural puncture despite evidence suggesting that epidural blood patch is more effective if performed after 24 to 48 hours [25]-[28]. Other surveys in North America as well as other continents show that this inconsistency in management exists all around the world [24] [29]-[33].

The thought behind using conservative therapy to treat PDPH is that the symptoms can be treated until the dural defect heals on its own. Many articles quote that $>85 \%$ of PDPH will resolve on its own without treatment. The source of this statistic is from a study in the 1950's, in which $72 \%$ of post-dural puncture headache resolved spontaneously by 1 week, and $86 \%$ by 6 weeks. In this study, patients were getting spinal anesthesia utilizing 22 gauge and 24 gauge cutting needles [13]. With the use of pencil point needles and smaller size needles, significant post-dural puncture headache after spinal anesthesia today is now negligible. A more common cause of post-dural puncture headache in the practice of anesthesia now is accidental dural puncture during epidural placement using Tuohy needles. Tuohy needles are generally 16, 17 or 18 gauge, thus making a larger defect than the needles used in the quoted study. This means that waiting for spontaneous resolution is likely not as reliable as traditionally thought when treating this type of PDPH. In fact, most of these patients likely will need definitive treatment with a blood patch. One institution published their 10 years' experience with PDPH where $>80 \%$ of their patients who developed headache after accidental dural puncture required blood patches [9].

\subsection{Preventive Measures to Reduce Incidence of Post-Dural Puncture Headache}

Over the years, physicians have tried many techniques to prevent accidental dural puncture and development of post-dural puncture headaches. In 2010, Apfel et al. published a quantitative review in the British Journal of Anaesthesia looking at strategies to prevent PDPH. Methods reviewed included epidural morphine, prophylactic epidural blood patch, intrathecal catheter, epidural saline, and intrathecal saline. This review found that epidural morphine use did significantly reduce the development of PDPH. The other methods either did not lead to significant reduction in PDPH when randomized controlled trials were analyzed or they did not have randomized controlled trial evidence available [34].

In 2013, a meta-analysis was published reviewing forty RCTs $(n=11,536$ epidural placements) that investigated measures to prevent PDPH [35]. The different methods studied included combined spinal-epidural (CSE), 
loss of resistance to air vs fluid, needle bevel orientation, different types of epidural needle, ultrasound guided insertion, prophylactic epidural blood patch, and continuous spinal anesthesia after a wet tap. In the meta-analysis, CSE, air vs fluid, ultrasound guidance, and continuous spinal after a wet tap did not make a significance difference in the incidence of post dural puncture headache. A separate meta-analysis study looking into continuous spinal after wet tap showed that although it does not reduce the incidence of PDPH, it does significantly reduce the need for an epidural blood patch [36]. Lateral orientation of the needle bevel (parallel to the vertebral column) during insertion was found to reduce the incidence of PDPH from $2.4 \%$ to $1.4 \%(\mathrm{P}<0.03)$ in one trial, but it was deemed to be of low quality in the meta-analysis [35] [37]. There were four randomized controlled trials looking into prophylactic blood patch. The prophylactic blood patch is performed by injecting $15-20 \mathrm{ml}$ of blood through the epidural catheter before pulling it. Three of the four RCTs analyzed showed a statistical difference in PDPH rate, but the one that did not show a difference was methodologically superior since it used a sham procedure to eliminate the placebo effect [35] [38]-[41]. More recently, another RCT investigated the effect of prophylactic epidural blood patch was published in 2014, and it did show a significant reduction the incidence of PDPH. However, the control group in this trial also did not receive a sham procedure and thus it cannot fully account for the placebo effect [42].

The use of intrathecal saline was investigated in 2001 by a non-randomized, non-blinded study, which showed that injecting $10 \mathrm{ml}$ normal saline through the epidural needle immediately after accidental puncture led to decreased incidence of PDPH and decreased need for blood patch [43]. Beside that study, there continues to be a lack of sufficient evidence to support the use of intrathecal saline in the setting of accidental dural puncture. Interestingly, an 18G special Sprotte epidural needle was invented to help reduce the incidence of PDPH. Using it did lead to a significant decrease in the development of PDPH compared to the $17 \mathrm{G}$ Tuohy (55.5\% vs 100\%), however, it also resulted in poorer loss of resistance, more failed block, and lower user satisfaction and thus cannot be recommended [44].

\subsection{Conservative Therapies}

Conservative treatments for PDPH are strategies short of performing an epidural blood patch aimed at preventing or stopping the patient's headache once dural puncture has occurred. Classically, these therapies include bed rest, aggressive hydration, caffeine, and NSAIDS. However, the evidences supporting these therapies are either lacking or highly equivocal. Carbaat et al. published a study in 1981 randomizing patients who received lumbar punctures to immediate mobilization versus 24 hours of bed rest showed no difference in the rate of PDPH [45]. Other studies since then on different populations have also showed no effect of bed rest of the rate of PDPH [46]-[48]. Of note, even though the recumbence position does not prevent PDPH, it can lessen the symptoms, and should be advised if symptoms are severe. With regards to keeping the patient hydrated, it is traditionally taught that it helps increase CSF production. There is no human study to support this claim, and in sheep, it has been shown that dehydration does not affect CSF production [49]. Furthermore, there is only one study looking into the effect of hydration (oral hydration) on PDPH and it shows that the headache is unaffected by the amount of hydration [50].

The question of whether caffeine is effective has been more studied than the effects of bed rest and hydration. A systemic review published in 2007 by Halker et al. devoted specifically to this question came to the conclusion that caffeine is ineffective in the treatment of PDPH [51]. As explained by Halker et al., some of the studies looking in the caffeine did find a degree of clinical effectiveness [52] [53], but was deemed to be methodologically flawed [51]. A randomized, double-blinded, placebo-controlled trial by Esaoglu et al. comparing oral caffeine-paracetamol to placebo showed no significant difference on PDPH [54]. More recently, a randomized, double-blinded, placebo controlled trial by Ragab and Facharzt in 2014 comparing intravenous caffeine with placebo shows that IV caffeine can be effective in reducing the rate and severity of PDPH [55]. It may be that intravenous caffeine is effective while oral caffeine is not. Like many of the other treatments for PDPH, until more studies are done, we are left to our clinical judgments as to when and how caffeine should be used.

There are other conservative therapies being studied that have also showed promising results. A prospective, randomized, double-blinded, placebo-controlled trial in which epidural morphine was administered as two $3 \mathrm{mg}$ dose 24 hours apart reduced the incidence of PDPH from $48 \%$ to $12 \%(\mathrm{P}=0.014)$ [56]. This result is very encouraging since epidural morphine is a therapy widely used to help with labor pain and has a good track record, 
thus can be easily adopted to help prevent PDPH. ACTH is thought to work by increasing CSF production and in a prospective, randomized, double-blinded, placebo-controlled trial, a 1mg IV bolus dose given prophylactically after accidental dural puncture decreased the incidence of PDPH from $68.9 \%$ to $33.3 \%(\mathrm{P}=0.001)$ [57]. In a randomized, double-blinded trial comparing IV ACTH to IV caffeine for the treatment of post-dural puncture headache found no difference in pain score between the two groups [58]. IV dexamethasone may reduce the incidence of PDPH based on a single-blinded randomized, control trial [59]; but in a double-blinded, randomized, placebo controlled trial, IV dexamethasone had no effect on the incidence of PDPH [60]. Frovatriptan may be effective in preventing PDPH based on a non-randomized, non-placebo controlled pilot study [61].

For the reduction of pain severity in patients with PDPH, gabapentin and pregabalin are newer therapies being studied. Gabapentin and pregabalin are widely used medications for neuropathic pain with good track records. Both medications have been shown to be effective in reducing the severity of pain associated with PDPH in their individual studies [62]-[65]. In a randomized study comparing gabapentin with pregabalin, both medications significantly reduced the severity of PDPH, and pregabalin was found to be the more effective of the two medications [66]. The typical dose of gabapentin used in these studies is $900 \mathrm{mg} /$ day and pregabalin is $150 \mathrm{mg} / \mathrm{day}$.

\subsection{Epidural Blood Patch}

It has been accepted for a long time that an epidural blood patch is the definitive treatment for PDPH [67]. The blood patch is an effective treatment in many cases, but there are still many questions surrounding it. In a singleblinded randomized controlled trial, the blood patch was significantly more effective than conservative treatment [68]. In a prospective study auditing 81 parturient with PDPH, 58 (72\%) patients received at least one therapeutic blood patch [28]. Of the patients requiring blood patches, $28 \%$ required more than one due to the return of symptoms. Complete relief of headache was achieved in $50 \%$ of patients who got blood patches, $38 \%$ got partial relief, and 12\% got no relief. The volume of blood used in this study varies between 7 to $25 \mathrm{ml}$ and there was no significant association between the volume of blood used and the success rate. In addition, they found that the initial rate of resolution did not differ whether the blood patch was done within 48 hours of dural puncture or after 48 hours of dural puncture; however, those that received the blood patch within 48 hours had a much higher recurrence rate ( $49 \%$ vs $11 \%, \mathrm{P}<0.001)$ [28]. Another study at a different institution showed similar success rate and a similar percentage of patient requiring more than one blood patches [69]. Although success rate after epidural blood patch is high, patients may have recurrence of symptoms after discharge. In a study of 87 patients requiring epidural blood patch, $71 \%$ had complete resolution on discharge; but in a follow up survey (73\% response rate), 57\% of respondents had return of symptoms after being discharged home [70].

In patients with persistent PDPH, they should be followed up closely because intracranial subdural hematoma is a rare, but potentially fatal complication. Subdural hematoma is usually caused by tears in the bridging veins, which can be stressed by traction when CSF volume is reduced. Although rare, there have been many case reports of subdural hematoma following dural puncture [71]-[78]. For cases of persistent PDPH resistant to conventional epidural blood patches, considerations should be given to fluoroscopically guided epidural blood patch, CT guided epidural blood patch, and surgical dura repair [79]-[81].

\section{Discussion}

We are currently in a time when standardized medical care is becoming more widespread. Standardization of care improves evidence-based practice as well as allows better communication and data collection between institutions [82]. As we adjust to medicine being more science-based, we must find algorithms or guidelines for the management of different diseases and complications. These algorithms should be based on sound scientific evidence. Scientific evidence evolves over time, and so should our practice. With regards to post-dural puncture headache, many physicians still manage it based on what they were taught in the past and not based on the best available evidence. Table 1 offers a guideline on how to manage post-dural puncture headache based on evidence available at this time. At our institution, an internal survey has shown that there is a wide variety in how we treat PDPH and is very similar to what was reported by Baysinger et al. [25] (unpublished data). We will start using the proposed guideline as shown in Table 1 to guide our practice decisions. The proposed guideline here may not be the best way to manage PDPH since the evidence for many of these therapies are equivocal, and some therapies are just beginning to be investigated. When more evidence is available, this guideline is sub- 
Table 1. Proposed guideline for management of dural puncture and PDPH. This guideline is based on up to date evidence described throughout this paper. Levels of evidence are divided as follow: (Ia) Evidence from meta-analysis of RCTs, (Ib) Evidence from at least one RCT, (IIa) Evidence from at least one well designed controlled trial which is not randomized, (IIb) Evidence from at least one well designed experimental trial, (III) Evidence from case, correlation, and comparative studies, (IV) Evidence from a panel of experts.

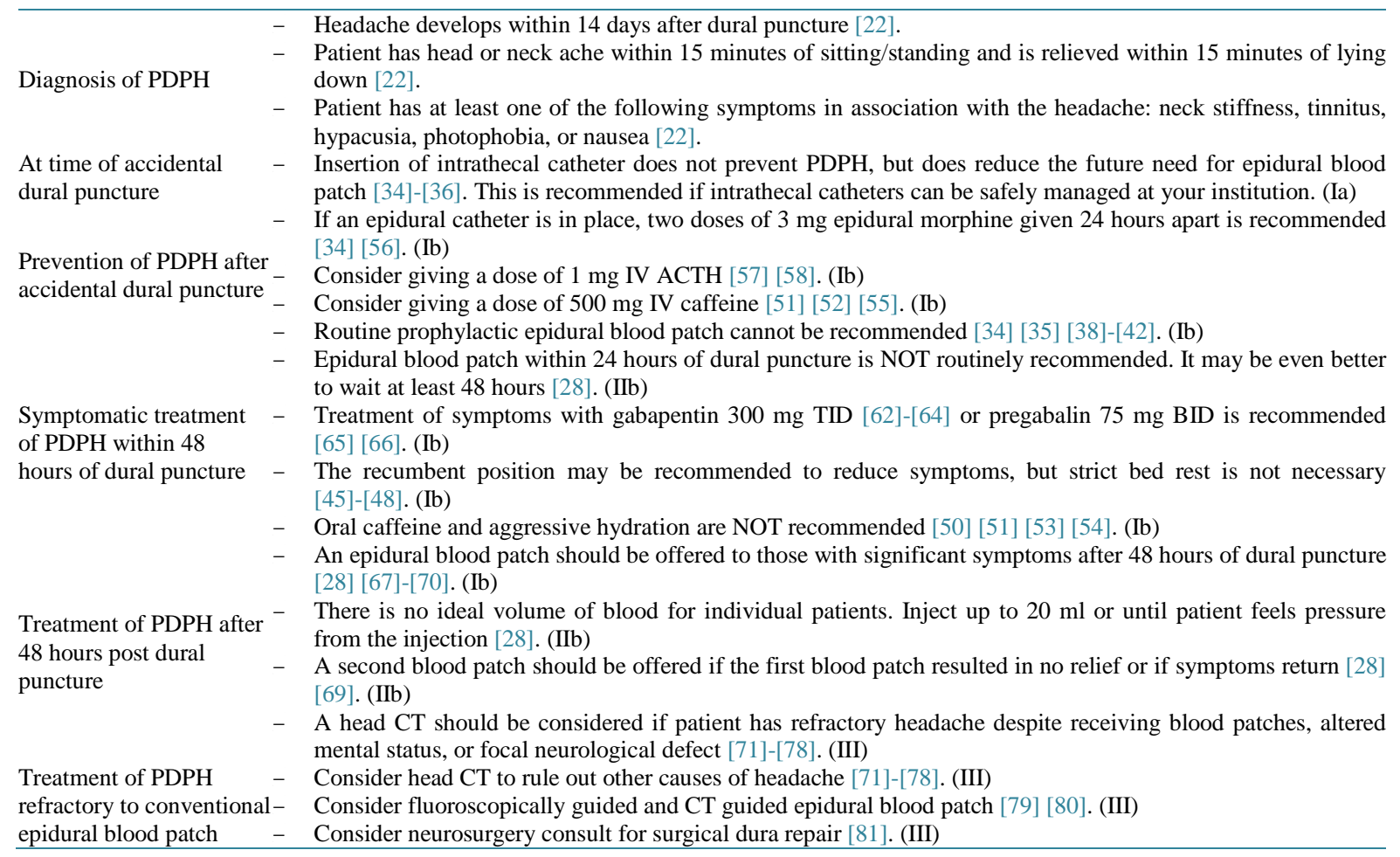

jected to change. But in the present, this guideline offers an opportunity for physicians to standardize their care to the available evidence. The end goal of this is to ultimately improve patient outcomes.

\section{References}

[1] Turnbull, D.K. and Shepherd, D.B. (2003) Post-Dural Puncture Headache: Pathogenesis, Prevention and Treatment. British Journal of Anaesthesia, 91, 718-729.

[2] Keener, E.B. (1959) An Experimental Study of Reactions of the Dura Mater to Wounding and Loss of Substance. Journal of Neurosurgery, 16, 424-447. http://dx.doi.org/10.3171/jns.1959.16.4.0424

[3] Grant, R., Condon, B., Hart, I. and Teasdale, G.M. (1991) Changes in Intracranial CSF Volume after Lumbar Puncture and Their Relationship to Post-LP Headache. The Journal of Neurology, Neurosurgery, and Psychiatry, 54, 440-442. http://dx.doi.org/10.1136/jnnp.54.5.440

[4] Costigan, S.N. and Sprigge, J.S. (1996) Dural Puncture: The Patient's Perspective. A Patient Survey of Cases at a DGH Maternity Unit 1983-1993. Acta Anaesthesiologica Scandinavica, 40, 710-714. http://dx.doi.org/10.1111/j.1399-6576.1996.tb04515.x

[5] Tourtelotte, W.W., Henderson, W.G., Tucker, R.P., Gilland, O., Walker, J.E. and Kokman, E. (1972) A Randomized, Double-Blind Clinical Trial Comparing the 22 versus 26 Guage Needle in the Production of Post-Lumbar Puncture Syndrome in Normal Individuals. Headache, 12, 73-78. http://dx.doi.org/10.1111/j.1526-4610.1972.hed1202073.x

[6] Carrie, L.E. (1990) Whitacre and Pencil-Point Needles: Some Points to Consider. Anaesthesia, 45, 1097-1098. http://dx.doi.org/10.1111/j.1365-2044.1990.tb14932.x

[7] Stocks, G.M., Wooller, D.J., Young, J.M. and Fernando, R. (2000) Postpartum Headache after Epidural Blood Patch: Investigation and Diagnosis. British Journal of Anaesthesia, 84, 407-410. http://dx.doi.org/10.1093/oxfordjournals.bja.a013451

[8] Choi, P.T., Galinski, S.E., Takeuchi, L., Lucas, S., Tamayo, C. and Jadad, A.R. (2003) PDPH Is a Common Complication of Neuraxial Blockade in Parturients: A Meta-Analysis of Obstetrical Studies. Canadian Journal of Anesthesia, 50, 
460-469. http://dx.doi.org/10.1007/BF03021057

[9] Van de Velde, M., Schepers, R., Berends, N., Vandermeersch, E. and De Buck, F. (2009) Ten Years of Experience with Accidental Dural Puncture and Post-Dural Puncture Headache in a Tertiary Obstetric Anaesthesia Department. International Journal of Obstetric Anesthesia, 17, 329-335. http://dx.doi.org/10.1016/j.ijoa.2007.04.009

[10] Sprigge, J.S. and Harper, S.J. (2008) Accidental Dural Puncture and Post Dural Puncture Headache in Obstetric Anaesthesia: Presentation and Management: A 23-Year Survey in a District General Hospital. Anaesthesia, 63, 36-43. http://dx.doi.org/10.1111/j.1365-2044.2007.05285.x

[11] Reynolds, F. (1993) Dural Puncture and Headache. British Medical Journal, 306, 874-876. http://dx.doi.org/10.1136/bmj.306.6882.874

[12] Leibold, R.A., Yealy, D.M., Coppola, M. and Cantees, K.K. (1993) Post-Dural-Puncture Headache: Characteristics, Management, and Prevention. Annals of Emergency Medicine, 22, 1863-1870. http://dx.doi.org/10.1016/S0196-0644(05)80416-0

[13] Vandam, L.D. and Dripps, R.D. (1956) Long-Term Follow-Up of Patients Who Received 10,098 Spinal Anesthetics. JAMA, 161, 586-591. http://dx.doi.org/10.1001/jama.1956.02970070018005

[14] Lybecker, H. and Andersen, T. (1995) Repetitive Hearing Loss Following Dural Puncture Treated with Autologous Epidural Blood Patch. Acta Anaesthesiologica Scandinavica, 39, 987-989. http://dx.doi.org/10.1111/j.1399-6576.1995.tb04211.x

[15] Schabel, J.E., Wang, E.D. and Glass, P.S. (2000) Arm Pain as an Unusual Presentation of Postdural Puncture Intracranial Hypotension. Anesthesia \& Analgesia, 91, 910-912. http://dx.doi.org/10.1097/00000539-200010000-00025

[16] Carrero, E.J., Agusti, M., Fabregas, N., Valldeoriola, F. and Fernandez, C. (1998) Unilateral Trigeminal and Facial Nerve Palsies Associated with Epidural Analgesia in Labour. Canadian Journal of Anaesthesia, 45, 893-897. http://dx.doi.org/10.1007/BF03012226

[17] Dunbar, S.A. and Katz, N.P. (1995) Post-Dural Puncture Thoracic Pain without Headache: Relief with Epidural Blood Patch. Canadian Journal of Anaesthesia, 42, 221-223. http://dx.doi.org/10.1007/BF03010681

[18] Eerola, M., Kaukinen, L. and Kaukinen, S. (1981) Fatal Brain Lesion Following Spinal Anaesthesia: Report of a Case. Acta Anaesthesiologica Scandinavica, 25, 115-116. http://dx.doi.org/10.1111/j.1399-6576.1981.tb01620.x

[19] Jack, T.M. (1979) Post-Partum Intracranial Subdural Haematoma: A Possible Complication of Epidural Analgesia. Anaesthesia, 34, 176-180. http://dx.doi.org/10.1111/j.1365-2044.1979.tb06274.x

[20] Pavlin, D.J., McDonald, J.S., Child, B. and Rusch, V. (1979) Acute Subdural Hematoma-An Unusual Sequel to Lumbar Puncture. Anesthesiology, 51, 338-339. http://dx.doi.org/10.1097/00000542-197910000-00012

[21] IHS Classification IHD-II. http://www.ihs-classification.org/en/02 klassifikation/03 teil2/07.02.01 nonvascular.html

[22] Savoie, K. (2014) New Criteria Suggested for Defining Postdural Puncture Headaches after Epidural. Pain Medicine News, 12.

http://www.painmedicinenews.com/ViewArticle.aspx?d=Clinical+Pain+Medicine\&d_id=82\&i=January+2014\&i_id=1 $\underline{028 \& \mathrm{a} \text { id }=24727}$

[23] Stein, G., Morton, J., Marsh, A., Collins, W., Branch, C., Desaga, U. and Ebeling, J. (1984) Headaches after Childbirth. Acta Neurologica Scandinavica, 69, 74-79. http://dx.doi.org/10.1111/j.1600-0404.1984.tb07782.x

[24] Gaiser, R.R. (2013) Postdural Puncture Headache: A Headache for the Patient and a Headache for the Anesthesiologist. Current Opinion in Anaesthesiology, 26, 263-303. http://dx.doi.org/10.1097/ACO.0b013e328360b015

[25] Baysinger, C.L., Pope, J.E., Lockhart, E.M. and Mercaldo, N.D. (2011) The Management of Accidental Dural Puncture and Postdural Puncture Headache: A North American Survey. Journal of Clinical Anesthesia, 23, 349-360. http://dx.doi.org/10.1016/j.jclinane.2011.04.003

[26] Month, R.C. (2011) Postdural Puncture Headache and the Arduous Quest to Teach Old Docs New Tricks. Journal of Clinical Anesthesia, 23, 347-348. http://dx.doi.org/10.1016/j.jclinane.2011.06.003

[27] Berrettini, W.H., Simmons-Alling, S. and Nurnberger, J.I. (1987) Epidural Blood Patch Does Not Prevent Headache after Lumbar Puncture. Lancet, 329, 856-857. http://dx.doi.org/10.1016/S0140-6736(87)91626-6

[28] Banks, S., Paech, M. and Gurrin, L. (2001) An Audit of Epidural Blood Patch after Accidental Dural Puncture with a Tuohy Needle in Obstetric Patients. International Journal of Obstetric Anesthesia, 10, 172-176. http://dx.doi.org/10.1054/ijoa.2000.0826

[29] Newman, M.J. and Cyna, A.M. (2008) Immediate Management of Inadvertent Dural Puncture during Insertion of a Labour Epidural: A Survey of Australian Obstetric Anaesthetists. Anaesthesia and Intensive Care, 36, 96-101.

[30] Harrington, B.E. and Schmitt, A.M. (2009) Meningeal (Postdural) Puncture Headache, Unintentional Dural Puncture, and the Epidural Blood Patch: A National Survey of United States Practice. Regional Anesthesia \& Pain Medicine, 34, 430-437. http://dx.doi.org/10.1097/AAP.0b013e3181b493e9 
[31] Darvish, B., Gupta, A., Alahuhta, S., Dahl, V., Helbo-Hansen, S., Thorsteinsson, A., Irestedt, L. and Dahlgren, G. (2011) Management of Accidental Dural Puncture and Post-Dural Puncture Headache after Labour: A Nordic Survey. Acta Anaesthesiologica Scandinavica, 55, 46-53. http://dx.doi.org/10.1111/j.1399-6576.2010.02335.x

[32] Marcus, H.E., Fabian, A., Dagtekin, O., Schier, R., Krep, H., Bottiger, B.W., Teschendorf, P., Spohr, F. and Petzke, F. (2011) Pain, Postdural Puncture Headache, Nausea, and Pruritis after Cesarean Delivery: A Survey of Prophylaxis and Treatment. Minerva Anestesiologica, 77, 1043-1049.

[33] Baraz, R. and Collin, R.E. (2005) The Management of Accidental Dural Puncture during Labour Epidural Analgesia: A Survey of UK Practice. Anaesthesia, 60, 673-679. http://dx.doi.org/10.1111/j.1365-2044.2005.04222.x

[34] Apfel, C.C., Saxena, A., Cakmakkaya, O.S., Gaiser, R., George, E. and Radke, O. (2010) Prevention of Postdural Puncture Headache after Accidental Dural Puncture: A Quantitative Systemic Review. British Journal of Anaesthesia, 105, 255-263. http://dx.doi.org/10.1093/bja/aeq191

[35] Bradbury, C.L., Singh, S.I., Badder, S.R., Wakely, L.J. and Jones, P.M. (2013) Prevention of Post-Dural Puncture Headache in Parturients: A Systemic Review and Meta-Analysis. Acta Anaesthesiologica Scandinavica, 57, 417-430. http://dx.doi.org/10.1111/aas.12047

[36] Heesen, M., Klohr, S., Rossaint, R., Walter, M., Straube, S. and van de Velde, M. (2013) Insertion of an Intrathecal Catheter Following Accidental Dural Puncture: A Meta-Analysis. International Journal of Obstetric Anesthesia, 22, 26-30. http://dx.doi.org/10.1016/j.ijoa.2012.10.004

[37] Norris, M.C., Leighton, B.L. and DeSimone, C.A. (1989) Needle Bevel Direction and Headache after Inadvertent Dural Puncture. Anesthesiology, 70, 729-731. http://dx.doi.org/10.1097/00000542-198905000-00002

[38] Ackerman, W.E., Juneja, M.M. and Kaczorowski, D.M. (1990) Prophylactic Epidural Blood Patch for the Prevention of Postdural Puncture Headache in the Parturient. Anesthesiology Review, 17, 45-49.

[39] Colonna-Romano, P. and Shapiro, B.E. (1989) Unintentional Dural Puncture and Prophylactic Epidural Blood Patch in Obstetrics. Anesthesia \& Analgesia, 69, 522-523. http://dx.doi.org/10.1213/00000539-198910000-00018

[40] Lowenwirt, I., Cohen, S., Zephyr, J., Harner, R., Hronkova, B. and Rovner, J.S. (1998) Can Prophylactic Epidural Blood Patch Reduce the Incidence and Severity of Postpartum Dural Puncture Headache in Obstetrics. Anesthesia \& Analgesia, 86, 378S. http://dx.doi.org/10.1097/00000539-199802001-00376

[41] Scavone, B.M., Wong, C.A., Sullivan, J.T., Yaqhmour, E., Sherwani, S.S. and McCarthy, R.J. (2004) Efficacy of a Prophylactic Epidural Blood Patch in Preventing Post Dural Puncture Headache in Parturients after Inadvertent Dural Puncture. Anesthesiology, 101, 1422-1427. http://dx.doi.org/10.1097/00000542-200412000-00024

[42] Stein, M.H., Cohen, S., Mohiuddin, M.A., Dombrovskiy, V. and Lowenwirt, I. (2014) Prophylactic vs Therapeutic Blood Patch for Obstetric Patients with Accidental Dural Puncture-A Randomized Controlled Trial. Anaesthesia, 69, 320-326. http://dx.doi.org/10.1111/anae.12562

[43] Charsley, M.M. and Abram, S.E. (2001) The Injection of Intrathecal Normal Saline Reduces the Severity of Postdural Puncture Headache. Regional Anesthesia \& Pain Medicine, 26, 301-305. http://dx.doi.org/10.1097/00115550-200107000-00004

[44] Morley-Forster, P.K., Singh, S., Angle, P., Littleford, J., Currin, M. and Halpern, S.H. (2006) The Effect of Epidural Needle Type on Postdural Puncture Headache: A Randomized Trial. Canadian Journal of Anesthesia, 53, 572-578. http://dx.doi.org/10.1007/BF03021847

[45] Carbaat, P.A. and van Crevel, H. (1981) Lumbar Puncture Headache: Controlled Study on the Preventive Effect of 24 Hours’ Bed Rest. Lancet, 318, 1133-1135. http://dx.doi.org/10.1016/S0140-6736(81)90586-9

[46] Tejavanija, S., Sithinamsuwan, P., Sithinamsuwan, N., Nidhinandana, S. and Suwantemee, J. (2006) Comparison of Prevalence of Post-Dural Puncture Headache between Six Hour-Supine Recumbence and Early Ambulation after Lumbar Puncture in Thai Patients: A Randomized Controlled Study. Journal of the Medical Association of Thailand, 89, 814-820.

[47] Dieterich, M. and Brandt, T. (1985) Is Obligatory Bed Rest after Lumbar Puncture Obsolete? European Archives of Psychiatry and Neurological Sciences, 235, 71-75. http://dx.doi.org/10.1007/BF00633475

[48] Kim, S.R., Chae, H.S., Yoon, M.J., Han, J.H., Cho, K.J. and Chung, S.J. (2012) No Effect of Recumbency Duration on the Occurrence of Post-Lumbar Puncture Headache with a 22G Cutting Needle. BMC Neurology, $12,1$. http://www.biomedcentral.com/content/pdf/1471-2377-12-1.pdf http://dx.doi.org/10.1186/1471-2377-12-1

[49] Chodobski, A., Szmydynger-Chodobska, J. and McKinley, M.J. (1998) Cerebrospinal Fluid Formation and Absorption in Dehydrated Sheep. American Journal of Physiology, 275, F235-F238.

[50] Dieterich, M. and Brandt, T. (1988) Incidence of Post-Lumbar Puncture Headache Is Independent of Daily Fluid Intake. European Archives of Psychiatry and Neurological Sciences, 237, 194-196. http://dx.doi.org/10.1007/BF00449906

[51] Halker, R.B., Demaerschalk, B.M., Wellik, K.E., Wingerchuk, D.M., Rubin, D.I., Crum, B.A. and Dodick, D.W. (2007) 
Caffeine for the Prevention and Treatment of Postdural Puncture Headache: Debunking the Myth. Neurologist, 13, 323-327. http://dx.doi.org/10.1097/NRL.0b013e318145480f

[52] Yucel, A., Ozyalcin, S., Talu, G.K., Yucel, E.C. and Erdine, S. (1999) Intravenous Administration of Caffeine Sodium Benzoate for Postdural Puncture Headache. Regional Anesthesia \& Pain Medicine, 24, 51-54. http://dx.doi.org/10.1097/00115550-199924010-00010

[53] Camann, W.R., Murray, R.S., Mushlin, P.S. and Lambert, D.H. (1990) Effects of Oral Caffeine on Postdural Puncture Headache: A Double-Blind, Placebo-Controlled Trial. Anesthesia \& Analgesia, 70, 181-184. http://dx.doi.org/10.1213/00000539-199002000-00009

[54] Esmaoglu, A., Akpinar, H. and Ugur, F. (2005) Oral Multidose Caffeine-Paracetamol Combination Is Not Effective for the Prophylaxis of Postdural Puncture Headache. Journal of Clinical Anesthesia, 17, 58-61. http://dx.doi.org/10.1016/j.jclinane.2004.04.003

[55] Ragab, A. and Facharzt, K.N. (2014) Caffeine, Is It Effective for Prevention of Postdural Puncture Headache in Young Adult Patients? Egyptian Journal of Anaesthesia, 30, 181-186. http://dx.doi.org/10.1016/j.egja.2013.11.005

[56] Al-Metwalli, R.R. (2008) Epidural Morphine Injections for Prevention of Post-Dural Puncture Headache. Anaesthesia, 63, 847-850. http://dx.doi.org/10.1111/j.1365-2044.2008.05494.x

[57] Hakim, S.M. (2010) Cosyntropin for Prophylaxis against Postdural Puncture Headache after Accidental Dural Puncture. Anesthesiology, 113, 413-420. http://dx.doi.org/10.1097/ALN.0b013e3181dfd424

[58] Zeger, W., Younggren, B. and Smith, L. (2012) Comparison of Cosyntropin versus Caffeine for Post-Dural Puncture Headaches: A Randomized Double-Blinded Trial. World Journal of Emergency Medicine, 3, 2012. http://dx.doi.org/10.5847/wjem.j.issn.1920-8642.2012.03.004

[59] Hamzei, A., Basiri-Moghadam, M. and Pasban-Noghabi, S. (2012) Effect of Dexamethasone on Incidence of Headache after Spinal Anesthesia in Cesarean Section. A Single Blind Randomized Controlled Trial. Saudi Medical Journal, 33, 948-953.

[60] Doroudian, M.R., Norouzi, M., Esmailie, M. and Tanhaeivash, R. (2011) Dexamethasone in Preventing Post-Dural Puncture Headache: A Randomized, Double-Blind, Placebo-Controlled Trial. Acta Anaesthesiologica Belgica, 62, 143146.

[61] Bussone, G., Tullo, V., d’Onofrio, F., Petretta, V., Curone, M., Frediani, F., Tonini, C. and Omboni, S. (2007) Frovatriptan for the Prevention of Postdural Puncture Headache. Cephalalgia, 27, 809-813. http://dx.doi.org/10.1111/j.1468-2982.2007.01327.x

[62] Wagner, Y., Storr, F. and Cope, S. (2012) Gabapentin in the Treatment of Post-Dural Puncture Headache: A Case Series. Anaesthesia and Intensive Care, 40, 714-718.

[63] Erol, D.D. (2006) The Effect of Oral Gabapentin on Postdural Puncture Headache. Acute Pain, 8, 169-173. http://dx.doi.org/10.1016/j.acpain.2006.08.042

[64] Erol, D.D. (2011) The Analgesic and Antiemetic Efficacy of Gabapentin or Ergotamine/Caffeine for the Treatment of Postdural Puncture Headache. Advances in Medical Sciences, 56, 25-29. http://dx.doi.org/10.2478/v10039-011-0009-z

[65] Huseyinoglu, U., Huseyinoglu, N., Hamurtekin, E., Aygun, H. and Sulu, B. (2011) Effect of Pregabalin on Post-DuralPuncture Headache Following Spinal Anesthesia and Lumbar Puncture. Journal of Clinical Neuroscience, 18, 13651368. http://dx.doi.org/10.1016/j.jocn.2011.02.029

[66] Moghaddam, M.J., Mirkheshti, A. and Yahyavi, P. (2011) Comparison between Analgesic Effect of Gabapentin and Pregabalin in Controlling Delayed Onset Post Dural Puncture Headache in Non-Pregnant Patients. European Journal of Anaesthesiology, 28, 203-204. http://dx.doi.org/10.1097/00003643-201106001-00657

[67] Olsen, K.S. (1987) Epidural Blood Patch in the Treatment of Post-Lumbar Puncture Headache. Pain, 30, $293-301$. http://dx.doi.org/10.1016/0304-3959(87)90017-0

[68] van Kooten, F., Oedit, R., Bakker, S.L. and Dippel, D.W. (2008) Epidural Blood Patch in Post Dural Puncture Headache: A Randomized, Observer-Blind, Controlled Clinical Trial. Journal of Neurology, Neurosurgery \& Psychiatry, 79, 553-558. http://dx.doi.org/10.1136/jnnp.2007.122879

[69] Williams, E.J., Beaulieu, P. and Jenkins, J.G. (1999) Efficacy of Epidural Blood Patch in the Obstetric Population. International Journal of Obstetric Anesthesia, 8, 105-109. http://dx.doi.org/10.1016/S0959-289X(99)80007-7

[70] Eustace, N., Hennessy, A. and Gardiner, J. (2004) The Management of Dural Puncture in Obstetrics and the Efficacy of Epidural Blood Patches. Irish Medical Journal, 97, 298-300.

[71] Zeidan, A., Farhat, O., Maaliki, H. and Baraka, A. (2006) Does Postdural Puncture Headache Left Untreated Lead to Subdural Hematoma? Case Report and Review of Literature. International Journal of Obstetric Anesthesia, 15, 50-58. http://dx.doi.org/10.1016/j.ijoa.2005.07.001 
[72] Schott, M., Gehrke, A., Gabb, M. and Jantzen, J.P. (2013) Subdurales Hämatomnach Duraperforation. Der Anaesthesist, 62, 392-395. http://dx.doi.org/10.1007/s00101-013-2160-3

[73] Skret-Magierlo, J., Barnas, E., Sek-Klebukowska, B., Nicpon, J. and Kloc, G. (2014) Intracranial Hematoma as the Cause of Headache after Subarachnoid Anesthesia for Cesarean Section-A Case Report. Ginekologia Polska, 85, 5861.

[74] Bisinotto, F.M., Dezena, R.A., Fabri, D.C., Abud, T.M. and Canno, L.H. (2012) Intracranial Subdural Hematoma: A Rare Complication Following Spinal Anesthesia: Case Report. Brazilian Journal of Anesthesiology, 62, 88-95. http://dx.doi.org/10.1016/S0034-7094(12)70107-1

[75] Sharma, S., Halliwell, R., Dexter, M., Mudaliar, Y. and Yee, K. (2010) Acute Subdural Haematoma in the Presence of an Intrathecal Catheter Placed for the Prevention of Post-Dural Puncture Headache. Anaesthesia and Intensive Care, 38, 939-941.

[76] Nepomuceno, R. and Herd, A. (2013) Bilateral Subdural Hematoma after Inadvertent Dural Puncture during Epidural Analgesia. Journal of Emergency Medicine, 44, e227-e230. http://dx.doi.org/10.1016/j.jemermed.2012.06.025

[77] Diemunsch, P., Balabaud, V.P., Petiau, C., Merescaux, C., Muller, A., Valfrey, J. and Treisser, A. (1998) Hématome sous Durai Bilatéral après Analgesie Péridurale. Canadian Journal of Anaesthesia, 45, 328-331. http://dx.doi.org/10.1007/BF03012023

[78] Kayacan, N., Arici, G., Karsli, B. and Erman, M. (2004) Acute Subdural Haematoma after Accidental Dural Puncture During Epidural Anaesthesia. International Journal of Obstetric Anesthesia, 13, 47-49. http://dx.doi.org/10.1016/j.ijoa.2003.06.001

[79] Kawaguchi, M., Hashizume, K., Watanabe, K., Inuoue, S. and Furuya, H. (2011) Fluoroscopically Guided Epidural Blood Patch in Patients with Postdural Puncture Headache after Spinal and Epidural Anesthesia. Journal of Anesthesia, 25, 450-453. http://dx.doi.org/10.1007/s00540-011-1135-2

[80] Ho, K.Y. and Gan, T.J. (2007) Management of Persistent Post-Dural Puncture Headache after Repeated Epidural Blood Patch. Acta Anaesthesiologica Scandinavica, 51, 633-636. http://dx.doi.org/10.1111/j.1399-6576.2007.01283.x

[81] Pouskoulas, C.D., Taub, E. and Ruppen, W. (2013) Successful Treatment of Post-Dural-Puncture Headache with Surgical Dura Repair Two Years after Spinal Anesthesia. Cephalalgia, 33, 1269-1271. http://dx.doi.org/10.1177/0333102413490348

[82] Lehman, C.U. and Miller, M.R. (2004) Standardization and the Practice of Medicine. Journal of Perinatology, 24, 135-136. http://dx.doi.org/10.1038/sj.jp.7211060

\section{Abbreviations}

ACTH: adrenocorticotropic hormone

CSF: cerebrospinal fluid

PDPH: post-dural puncture headache

NSAIDS: nonsteroidal anti-inflammatory drugs

RCT: randomized controlled trial

CSE: combined spinal-epidurals

IV: intravenous 
Scientific Research Publishing (SCIRP) is one of the largest Open Access journal publishers. It is currently publishing more than 200 open access, online, peer-reviewed journals covering a wide range of academic disciplines. SCIRP serves the worldwide academic communities and contributes to the progress and application of science with its publication.

Other selected journals from SCIRP are listed as below. Submit your manuscript to us via either submit@scirp.org or Online Submission Portal.
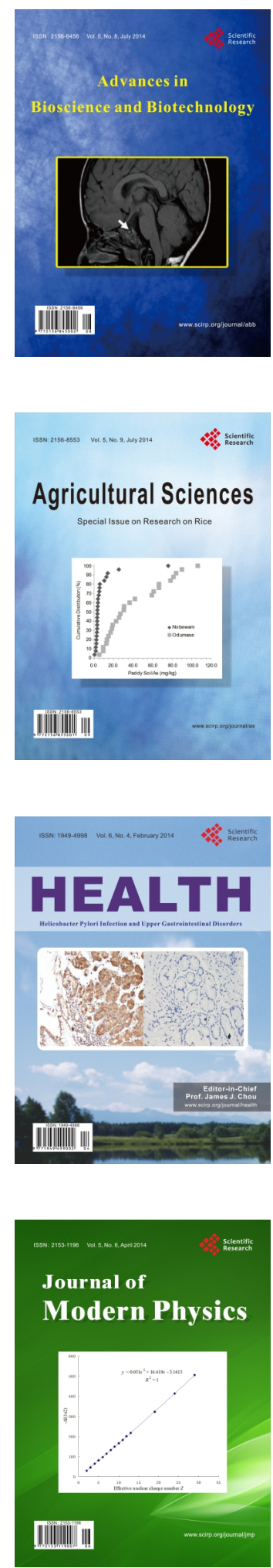
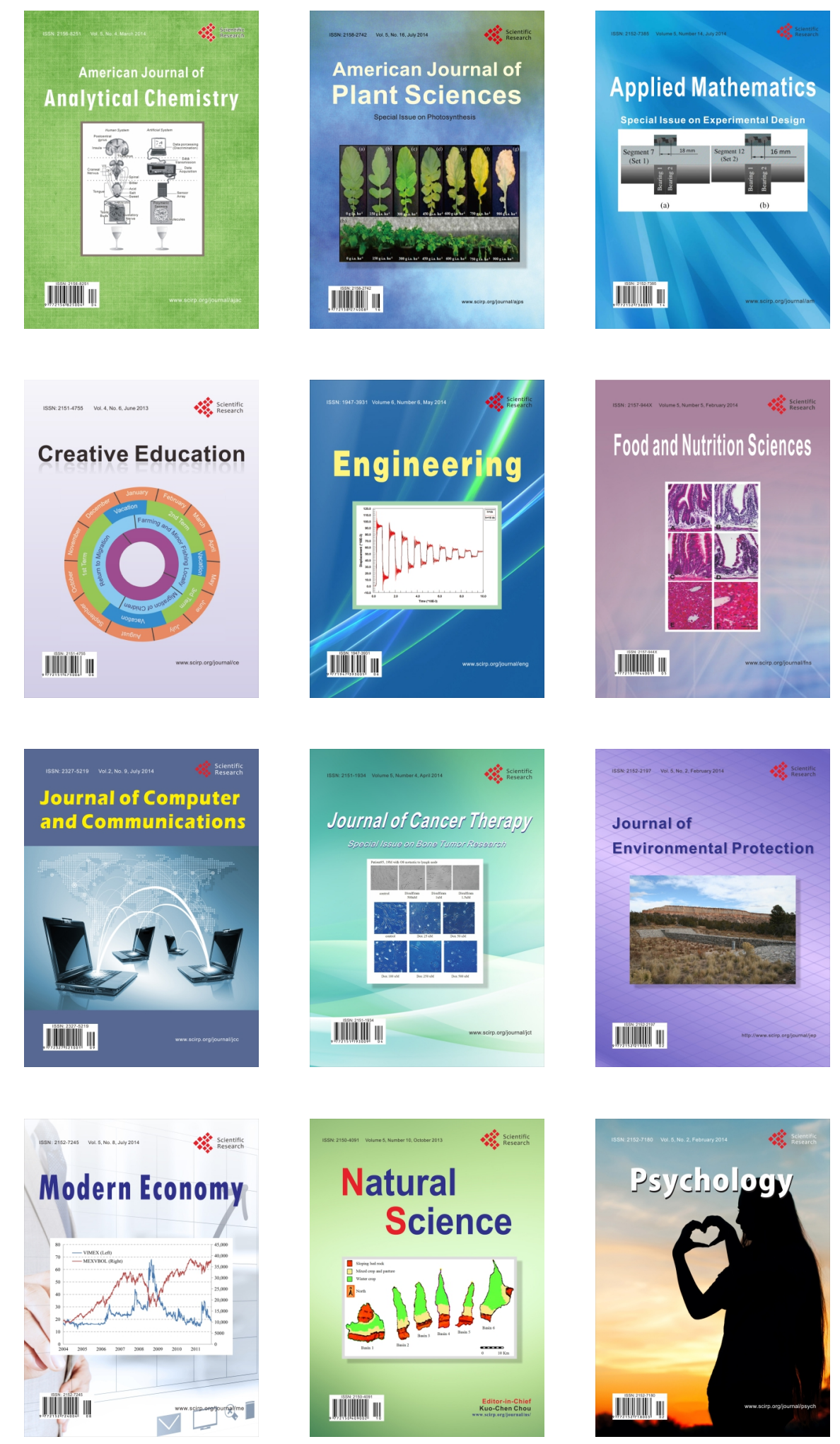